\title{
Physicochemical Characterization and Dissolution Study of Ibuprofen Compression-Coated Tablets Using Locust Bean Gum
}

\author{
Negar Bashardoust ${ }^{1,2}$, J. Josephine Leno Jenita ${ }^{1}$, \\ and Parvin Zakeri-Milani ${ }^{3, *}$ \\ 'Department of Pharmaceutics, Dayananda Sagar College of Pharmacy, Kumaraswamy, \\ Layout, Bangalore - 560078, Karnataka, India \\ ${ }^{2}$ Student Research Committee, Tabriz University of Medical Sciences, Tabriz, Iran \\ ${ }^{3}$ Drug Applied Research Center and Faculty of Pharmacy, Tabriz University of Medical Sciences, Tabriz, Iran
}

\begin{abstract}
The aim of the present study was to minimize drug release in the upper gastro intestinal tract and target the colon using the principles of compression coating. Compression-coated tablets of ibuprofen were prepared by a direct compression method using locust bean gum (LBG) at 300,250,200, and $175 \mathrm{mg}$. Tablets were evaluated for their physicochemical properties and in vitro drug release. In vitro drug release studies were performed with and without rat caecal contents. In rat caecal contents, tablets showed enhanced drug release due to degradation of the LBG coating by colonic enzymes. The in vitro release studies in $\mathrm{pH} 6.8$ phosphate buffer containing $2 \% \mathrm{w} / \mathrm{v}$ rat caecal contents showed the cumulative percentage release of ibuprofen after $26 \mathrm{~h}$ as $39.91 \pm 0.05 \%, 53.21 \pm 0.37 \%, 69.17 \pm 0.19 \%$, and $94.46 \% \pm 0.92 \%$. Coating thickness and the amount of chitosan control the release rate. Formulations were best fitted with Korsmeyer-Peppas kinetics, and the mechanism of drug release was non-Fickian super case II transport. FTIR studies reveal there is no drug-polysaccharide interaction. The $F_{1}$ formulation is a promising system for drug targeting to the colon.
\end{abstract}

\section{INTRODUCTION}

c olonic delivery refers to targeting drugs to the colon for treatment of its local diseases. It is also considered as an oral delivery method for drugs that are unstable, unabsorbed in the upper Gl tract, or both. Additionally, the other category of drugs targeted to this site includes drugs that need delayed absorption from a therapeutic point of view. This site of the Gl tract presents a nearly neutral $\mathrm{pH}$, longer residence time, and less enzymatic activity, which makes it less hostile compared with the proximal part of the GIT (1).

There are several pharmaceutical approaches to prepare colon-targeted drug delivery systems. These approaches could be categorized in two main classes (2). The first is covalent linkage of the drug with a carrier to make conjugates, and the second approach is delivering intact molecules to the colon. The second approach itself is subdivided into seven subclasses. These include systems developed using polymer coatings ( $\mathrm{pH}$-sensitive, biodegradable polymers), systems embedded in matrices (biodegradable matrices, hydrogels, $\mathrm{pH}$-sensitive matrices), time-released systems, systems with redox-sensitive polymers, bioadhesive systems, microparticle-coated systems, and osmotic controlled-delivery systems $(2,3)$.

Locust bean gum (LBG), also known as carob gum, is a galactomannan vegetable gum derived from the seeds of the leguminous plant Ceratonia siliqua Linn belonging

${ }^{*}$ Corresponding author. to the family Fabaceae (4). It consists chiefly of high molecular weight hydrocolloidal polysaccharides composed of galactose and mannose units (1:4) combined through glycosidic linkages. This natural, non-starch polysaccharide forms water-insoluble films that degrade in colonic microflora, making it useful in a colon-targeting strategy (5). On the other hand, LBG has various properties that make it a good choice in drug delivery: (1) it is biocompatible, biosorbable, biodegradable, cheap, and abundant; (2) it is nonteratogenic and nonmutagenic according to Joint FAO/WHO Expert Committee on Food Additives held in Geneva, April 1975; (3) it has acceptable shelf-life; and (4) its degradation products are excreted readily (4).

The aim of the present study was to develop a new colon-specific, compression-coated formulation for ibuprofen using LBG as coating material. Ibuprofen, a non-steroidal anti-inflammatory agent, was selected for formulation because of its most common adverse effect, gastrointestinal discomfort. Moreover, it is well absorbed throughout the colon and also reported to decrease both tumor growth and metastatic potential in mice $(6,7)$.

\section{MATERIALS AND METHODS}

Ibuprofen was obtained from Strides Acro Labs, Bangalore, India. Locust bean gum was purchased from Alembic Pharma, Baroda, India. Sodium hydroxide pellets were received from SD Fine-Chem. Ltd., Mumbai, India. 
Talc was obtained from Leo Chem., Bangalore, India. Potassium chloride and potassium bromide (IR grade) were from Thomas Baker, Mumbai, India and Merck specialities Pvt. Ltd., Germany, respectively. Microcrystalline cellulose, sodium starch glycolate, potassium dihydrogen phosphate, and magnesium stearate were obtained from Spectrochem Pvt. Ltd., Mumbai. Hydrochloric acid $(\mathrm{HCl})$ was provided by Swastik Pharmaceuticals, Mumbai, India. The instruments used were as follows: FTIR spectrometer (FTIR-8400S, Shimadzu, Japan), UV-vis spectrophotometer (UV-1800, Shimadzu, Japan), Disso DS 14000 dissolution test apparatus (Lablndia, India), C-DS 3 disintegration test apparatus (Serwell Instruments Inc., Bangalore, India), 12-station tablet compression machine (IP/BP/USP standard, Karnavati Engineering, Ahmedabad, India), hot-air oven (Serwell Instruments Inc., Bangalore, India), ATL-224-I digital balance (Acculab Sartorius Group, Bangalore, India), Shore Hardness Tester model HT-6510A (Scientific Engineering Corp., Delhi, India), hydraulic pellet press model KP-974 (S. V. Scientific), pH meter (Serwell Instrument Inc., Bangalore, India), FT-20 friability tester (Dutta Scientific Works., Madras, India), and CHM-6 Plus humidity cabinet (Remi Laboratories Ltd., India).

\section{Preparation of Optimized Core Tablets of Ibuprofen}

Each core tablet for in vitro studies consisted of ibuprofen (100 mg), dried starch (4 mg), and microcrystalline cellulose (MCC, $46 \mathrm{mg}$ ). Starch was added to obtain quickly disintegrating tablets. All materials were weighed, mixed, and passed through a $250-\mu \mathrm{m}$ mesh to ensure complete mixing. The tablets were prepared by compressing the thoroughly mixed materials using 7-mm round, flat, plain punches on a single-station tablet machine (Cadmach, India). The thickness of the core tablets was $0.2 \mathrm{~mm}$, and their crushing strength was about $3 \mathrm{~kg} / \mathrm{cm}^{2}$.

\section{Compression Coating of Ibuprofen Core Tablets}

The coating material, consisting of different amounts of LBG $(270,220,170,145$, and $120 \mathrm{mg})$, was compressed on the previously prepared core tablet, which

Table 1. Composition of Locust Bean Gum Coats Used to Cover Ibuprofen Core Tablets

\begin{tabular}{cccccc}
\hline \multirow{2}{*}{$\begin{array}{c}\text { Batch } \\
\text { code }\end{array}$} & $\begin{array}{c}\text { Coat Weight } \\
(\mathbf{m g})\end{array}$ & LBG & MCC & Mg Stearate & Talc \\
\hline $\mathbf{F}_{\mathbf{1}}$ & 300 & 270 & 25 & 2 & 3 \\
\hline $\mathbf{F}_{\mathbf{2}}$ & 250 & 220 & 25 & 2 & 3 \\
\hline $\mathbf{F}_{\mathbf{3}}$ & 200 & 170 & 25 & 2 & 3 \\
\hline $\mathbf{F}_{\mathbf{4}}$ & 175 & 145 & 25 & 2 & 3 \\
\hline $\mathbf{F}_{\mathbf{5}}$ & 150 & 120 & 25 & 2 & 3 \\
\hline
\end{tabular}

was carefully placed in the center of the die cavity (Table1). The compression pressure was $5000 \mathrm{~kg}$, and the strength of the compression-coated tablets was 5 $\mathrm{kg} / \mathrm{cm}^{2}$. The resulting coating had adequate hardness due to the use of microcrystalline cellulose in the coating formulation.

\section{Characterization of Compression-Coated Tablets}

Prepared tablets were subjected to quality control tests including hardness, friability, weight variation, and uniformity of drug content tests. These studies were carried out according to USP methods (8).

\section{Drug Release Studies in the Presence and Absence of Rat Caecal Contents}

In the first step, drug release from tablets was characterized using the USP basket dissolution apparatus and $900 \mathrm{~mL}$ of acidic buffer $(0.1 \mathrm{~N} \mathrm{HCl}, \mathrm{pH} 1.2)$ and $\mathrm{pH} 7.4$ phosphate buffer as test media for $2 \mathrm{~h}$ and 3 $\mathrm{h}$, respectively. A stirring speed of $100 \mathrm{rpm}$ was used. Two samples of $1 \mathrm{~mL}$ were withdrawn and immediately filtered. Drug concentration was measured spectrophotometrically.

In the next step, release profiles were examined using the rat caecal contents as dissolution medium (9) to check whether tablet cores might be affected as the dosage form passes through the GI tract. Drug release studies in the presence of caecal contents were carried out using USP Apparatus 1 with a slight modification in procedure. The experiments were carried out in $200-\mathrm{mL}$ beakers immersed in water contained in the $1000-\mathrm{mL}$ vessel that was maintained in the water bath of the dissolution test apparatus. Initial studies were carried out in $200 \mathrm{~mL}$ of $0.1 \mathrm{~N} \mathrm{HCl}$ (pH 1.2) for $2 \mathrm{~h}$. After this, the dissolution medium was replaced with $200 \mathrm{~mL}$ of $\mathrm{pH}$ 7.4 phosphate buffered saline (PBS), and the dissolution continued for another $3 \mathrm{~h}$. Then a drug release study was carried out in $\mathrm{pH} 6.8$ buffer medium containing $2 \% \mathrm{w} / \mathrm{v}$ rat caecal contents for $21 \mathrm{~h}\left(100 \mathrm{rpm}, 37^{\circ} \mathrm{C}\right)$. As the caecum is naturally anaerobic, all experiments in caecal content media were conducted under a continuous supply of nitrogen. At different time intervals, 1-mL samples were withdrawn from the dissolution medium and replenished with $1 \mathrm{~mL}$ of $2 \% \mathrm{w} / \mathrm{v}$ caecal contents maintained under anaerobic conditions to maintain a constant volume. The samples were diluted and analyzed spectrophotometrically. The Institutional Animal Ethics Committee approved the experimental protocol for preparation of rat caecal contents. Briefly, five Wister rats weighing between 200 and $300 \mathrm{~g}$ were kept on a normal diet and administered $1 \mathrm{~mL}$ of $2 \% \mathrm{w} / \mathrm{v}$ solution of LBG in water through Teflon tubing placed directly into stomach region via the oral cavity. After pretreatment for 7 days with locust bean gum dispersion, the rats were sacrificed by spinal traction thirty minutes before the release studies. Then the caecal 
contents were collected and transferred into pH 6.8 PBS solution previously bubbled with $\mathrm{CO}_{2}$ to make a final caecal dilution of $2 \% \mathrm{w} / \mathrm{v}(6,9)$.

\section{FTIR Studies}

An FTIR study was performed to determine the compatibility of drug and excipients. Briefly, $10 \mathrm{mg}$ of sample and $400 \mathrm{mg}$ of $\mathrm{KBr}$ were placed in a mortar and triturated. A small amount of the triturated sample was taken into a pellet maker and compressed at $10 \mathrm{~kg} / \mathrm{cm}^{2}$ using a hydraulic press. The pellet was kept in the sample holder and scanned from 4000 to $400 \mathrm{~cm}^{-1}$ in a Shimadzu FTIR spectrophotometer. Samples of ibuprofen, LBG, and a physical mixture of drug and polymer were prepared. The spectra obtained were compared and interpreted for the functional group peaks.

\section{Evaluation of Release-Rate Kinetics}

To investigate the mode of release from tablets, the release data were analyzed using the following mathematical models:

Zero-order kinetics

$Q=Q_{0}-K_{0} t$

First-order kinetics

$\ln Q=\ln Q_{0}-K_{1} t$

Higuchi equation

(square root of time equation)

Hixson-Crowell cube-root law

Peppas equation

$$
Q=K_{2} t^{1 / 2}
$$

$$
\begin{aligned}
& Q_{0}{ }^{1 / 3}-Q_{t}{ }^{1 / 3}=K_{3} t \\
& Q / Q_{0}=K t_{n}
\end{aligned}
$$

where $K_{0}, K_{1}, K_{2}$, and $K_{3}$ are release rate constants, $Q / Q_{0}$ is the fraction of drug released at time $t, Q_{0}$ is the initial amount of drug, $Q_{t}$ is the amount of drug released at time $t, K$ is a constant, and $n$ is a diffusion constant that indicates general operating release mechanism. The exponent $n$ is calculated through the slope of the straight line (Table 2), which indicates the mechanism of drug release (10-12).

\section{RESULTS AND DISCUSSION}

Fourier-transform infrared (FTIR) spectra were scanned over the wavenumber range of $3600-400 \mathrm{~cm}^{-1}$. They showed characteristic peaks of ibuprofen at $1716 \mathrm{~cm}^{-1}$ and $2943 \mathrm{~cm}^{-1}$ due to carbonyl and hydroxyl stretching, respectively. For pure locust bean gum, the band at $3427 \mathrm{~cm}^{-1}$ is due to $\mathrm{O}-\mathrm{H}$ stretching. The band at 2926 $\mathrm{cm}^{-1}$ represents $\mathrm{C}-\mathrm{H}$ stretching of the $-\mathrm{CH}_{2}$ groups. The bands due to ring stretching of galactose and mannose appear at $1657 \mathrm{~cm}^{-1}$. Moreover, the bands in the region of $1350-1450 \mathrm{~cm}^{-1}$ show the symmetrical deformations of

Table 2. Mechanism of Drug Release and the Relevant $n$ Value in Peppas Equation

\begin{tabular}{lc}
\hline Type of Mechanism & $\boldsymbol{n}$ value \\
\hline Fickian diffusion & $<0.5$ \\
\hline Supercase Il transport & $>1$ \\
\hline Non-Fickian diffusion & $0.5-1$ \\
\hline
\end{tabular}

the $\mathrm{CH}_{2}$ and $\mathrm{COH}$ groups. The bands representing the primary alcoholic $-\mathrm{CH}_{2} \mathrm{OH}$ stretching mode and $\mathrm{CH}_{2}$ twisting vibrations appear at 1078 and $1024 \mathrm{~cm}^{-1}$, respectively (13). The peaks of the spectra for ibuprofen, the polysaccharide (LBG), and their physical mixture were the same, so no drug-polysaccharide interaction was observed (Figure 1).

Table 3 shows the physicochemical parameters evaluated for ibuprofen compression-coated and core tablets.

The tablets were evaluated for weight variation, hardness, and friability. The hardness was from $4.5 \pm 0.42$ to $5.0 \pm 0.24 \mathrm{~kg} / \mathrm{cm}^{2}$, and in all cases the friability was less than $1 \%$. The drug content for core ibuprofen tablets was $97.84 \pm 0.15 \%$. The results showed that the percent weight variation of formulations ranged from $0.48 \pm 0.023 \%$ to $1.40 \pm 0.012 \%$. This indicates that there was no significant weight variation in all prepared formulations. Therefore, the compression-coated tablets complied with

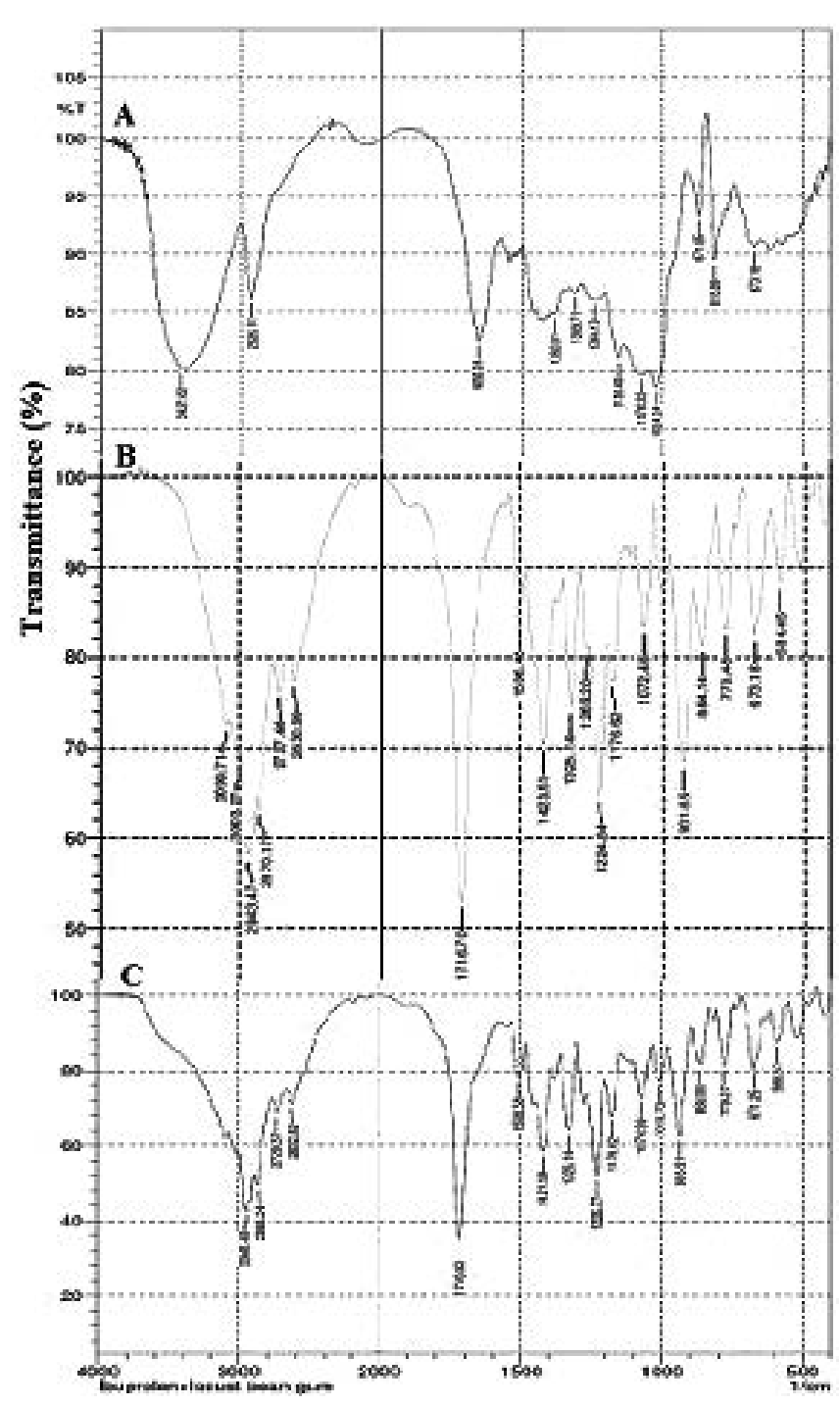

Figure 1. IR spectra of (A) locust bean gum, (B) ibuprofen, and (C) their physical mixture. 
Table 3. Physicochemical Evaluations of Compression-Coated and Core Ibuprofen Tablets

\begin{tabular}{cccc}
\hline Formulation & $\begin{array}{c}\text { Hardness } \\
\left(\mathbf{k g} / \mathbf{c m}^{\mathbf{2}} \mathbf{\pm} \mathbf{S D}\right)\end{array}$ & $\begin{array}{c}\text { Friability } \\
(\% \pm \mathbf{S D})\end{array}$ & $\begin{array}{c}\text { Weight variation } \\
(\% \pm \mathbf{S D})\end{array}$ \\
\hline Core tablet & $4.6 \pm 0.42$ & $0.20 \pm 0.021$ & $1.40 \pm 0.012$ \\
\hline $\mathbf{F}_{\mathbf{1}}$ & $5.0 \pm 0.24$ & $0.06 \pm 0.021$ & $0.68 \pm 0.034$ \\
\hline $\mathbf{F}_{\mathbf{2}}$ & $4.9 \pm 0.13$ & $0.08 \pm 0.015$ & $0.63 \pm 0.052$ \\
\hline $\mathbf{F}_{\mathbf{3}}$ & $4.7 \pm 0.42$ & $0.07 \pm 0.016$ & $0.54 \pm 0.074$ \\
\hline $\mathbf{F}_{\mathbf{4}}$ & $4.7 \pm 0.18$ & $0.06 \pm 0.014$ & $0.48 \pm 0.023$ \\
\hline $\mathbf{F}_{\mathbf{5}}$ & $4.5 \pm 0.42$ & $0.07 \pm 0.021$ & $0.37 \pm 0.048$ \\
\hline
\end{tabular}

pharmaceutical quality control standards. The in vitro release profiles of drug from tablets in the presence and absence of rat caecal contents are shown in Figures 2 and 3 , respectively. Generally, drug release from LBG-coated tablets in the medium containing rat caecal contents was higher than that in $\mathrm{pH} 6.8$ phosphate buffer. This result is due to the enzymatic degradation of coating material by colonic bacteria. It is also noted that drug release from tablets decreases with increased LBG levels (i.e., formulations with highest amount of polysaccharide in the coat, $F_{1}$ ) represented only $39.9 \pm 0.05 \%$ drug released in the presence of caecal contents in which $94.46 \pm 0.92 \%$ drug release was observed for $\mathrm{F}_{4}$ with lowest level of LBG. The same trend was observed in the drug release experiments in the absence of caecal contents. This is confirmed by the findings of a study by Chithaluru et al. (10) in which ketorolac tromethiamine compression-coated tablets were prepared using guar gum/metalose $90 \mathrm{SH}$. Based on their results, a smaller amount of guar gum as a microbially triggered coating leads to a thinner coating and a higher drug release rate. The percent drug released from tablets coated with coating formulation $\mathrm{F}_{3}$ increased from $18 \mathrm{~h}$ onward, indicating the commencement of the breaking of gum coats. $\mathrm{F}_{4}$ follows this same trend. The percent drug released after $26 \mathrm{~h}$ of testing was $69.17 \%$, and the tablet coating was broken at one point making way for the release of the drug. Moreover, the drug in tablets was not released until $5 \mathrm{~h}$, which indicates that ibuprofen was not released in $0.1 \mathrm{~N} \mathrm{HCl}$ and $\mathrm{pH} 7.4$ phosphate buffer. This observation confirms the protective effect of LBG for drug to be intact in stomach and upper intestine during its $\mathrm{Gl}$ transit time.

In earlier studies (14), a polymer blend consisting of HPMC K4M as a drug-release retarding agent in combination with colon degradable polysaccharide guar gum was successfully used to protect ibuprofen from release under conditions mimicking mouth-to-colon transit. In our previous study (15), almost the same result was observed for ibuprofen compression-coated tablets using chitosan.

The stability of three formulations having $175 \mathrm{mg}$ LBG in the coating material was studied under the accelerated

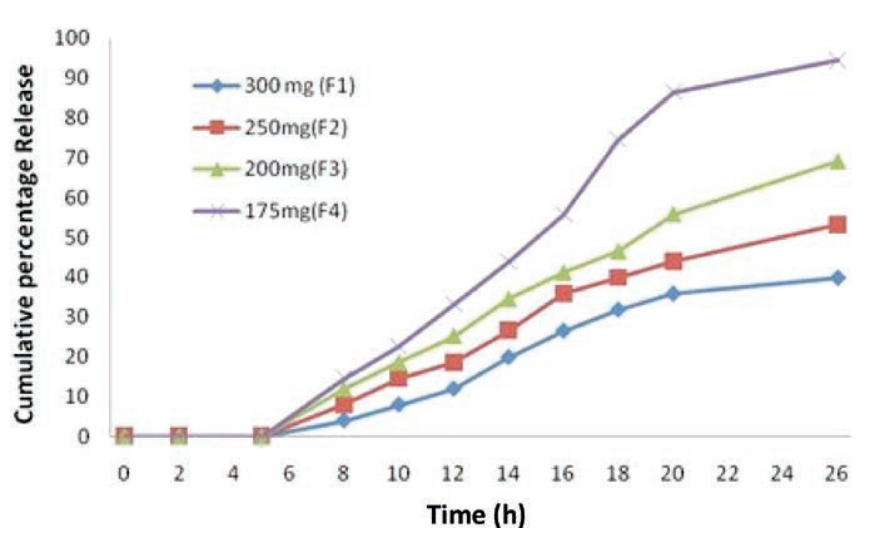

Figure 2. Cumulative percent release profile of ibuprofen in formulations $F_{1}$ to $\mathrm{F}_{4}$ using rat caecal content.

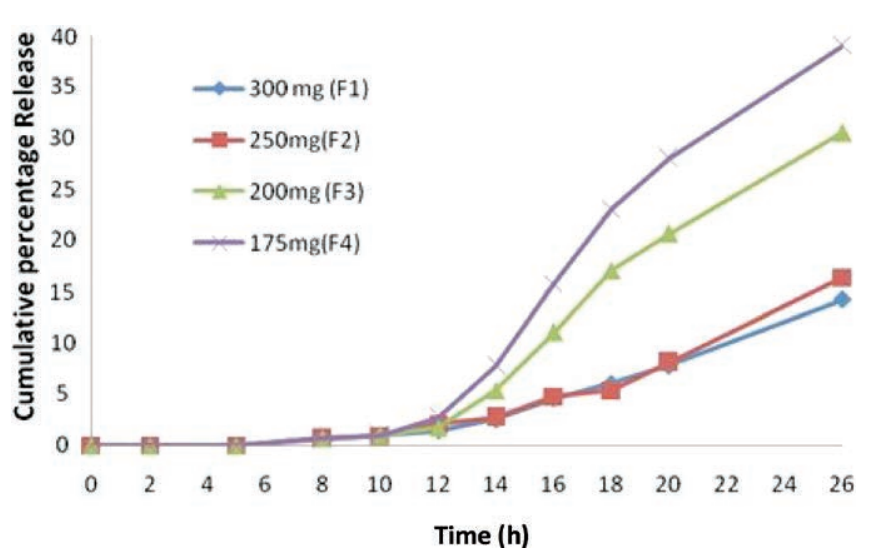

Figure 3. Cumulative percent release profile of ibuprofen in formulations $F_{1}$ to $\mathrm{F}_{4}$ without rat caecal content.

conditions at $40{ }^{\circ} \mathrm{C}$ and $75 \%$ relative humidity in a humidity cabinet. During the stability test, the characteristics of the compression-coated tablets and percent cumulative drug release (CDR) were evaluated on days 10,20 , and 30. Table 4 shows the tablet characteristics during the storage time in the stability chamber versus those of formulations kept in ambient conditions as a control group. There were no significant changes in drug content from the control tablets, and average drug content in samples was greater than $99 \%$ of label claim. In vitro drug release studies also showed no noteworthy alteration in percent CDR during the stability test. In other words, at the end of test period more than $93.53 \%$ drug was released from tablets compared with $94.46 \%$ and $94.36 \%$ for the initial value and tablets at ambient conditions, respectively. All other evaluated characteristics including physical appearance, average weight, and hardness of tablets were also unchanged during the period.

The results of various kinetics models and the mechanism of drug release from ibuprofen compression-coated tablets are shown in Table 5. To determine the mechanism 
Table 4. Stability Data of Compression-Coated Ibuprofen Tablets with 175 mg Locust Bean Gum in Coating $\left(F_{4}\right)$

\begin{tabular}{|c|c|c|c|c|c|c|c|}
\hline \multirow[b]{3}{*}{ Evaluation parameter } & \multicolumn{7}{|c|}{ Observation in Day } \\
\hline & \multirow[b]{2}{*}{ Initial } & \multicolumn{3}{|c|}{ Room temperature } & \multicolumn{3}{|c|}{$45^{\circ} \mathrm{C} / 75 \%$ RH } \\
\hline & & 10 & 20 & 30 & 10 & 20 & 30 \\
\hline Physical appearance & Coated tablets & No change & No change & No change & No change & No change & No change \\
\hline Average weight (mg) & 177 & 179 & 182 & 178 & 177 & 179 & 180 \\
\hline Hardness $\left(\mathbf{k g} / \mathrm{cm}^{2}\right)$ & 4.7 & 4.7 & 4.8 & 4.8 & 4.6 & 4.6 & 4.5 \\
\hline Drug content $^{a}(\% \mathrm{w} / \mathrm{w} \pm \mathrm{SD})$ & 100 & $98.54 \pm 0.12$ & $99.51 \pm 0.08$ & $99.42 \pm 0.09$ & $99.84 \pm 0.13$ & $99.47 \pm 0.14$ & $99.56 \pm 0.10$ \\
\hline$\%$ CDR $^{a}$ & $94.46 \pm 0.92$ & $94.36 \pm 0.08$ & $94.57 \pm 0.15$ & $94.08 \pm 0.23$ & $94.64 \pm 0.35$ & $93.72 \pm 0.19$ & $93.53 \pm 0.45$ \\
\hline
\end{tabular}

a initial drug content as $100 \% \mathrm{w} / \mathrm{w}(n=3)$

Table 5. Release Kinetics of Ibuprofen from Compression-Coated Tablets with Locust Bean Gum Coating

\begin{tabular}{|c|c|c|c|c|c|c|c|c|c|c|c|c|c|c|c|}
\hline \multirow[b]{2}{*}{ Formulation } & \multicolumn{3}{|c|}{ First-order } & \multicolumn{3}{|c|}{ Zero-order } & \multicolumn{3}{|c|}{ Higuchi } & \multicolumn{4}{|c|}{ Peppas } & \multicolumn{2}{|c|}{ Hixon-Crowel } \\
\hline & $R^{2}$ & $k_{1}$ & MPE & $R^{2}$ & $k_{0}$ & MPE & $R^{2}$ & $k_{\mathrm{H}}$ & MPE & $R^{2}$ & $k_{\mathrm{p}}$ & $n$ & MPE & $R^{2}$ & MPE \\
\hline $\mathbf{F}_{1}$ & 0.949 & 0.0291 & 12.81 & 0.931 & 0.0222 & 17.86 & 0.959 & 0.1785 & 11.44 & 0.931 & 0.0007 & 2.06 & 16.99 & 0.943 & 14.63 \\
\hline $\mathbf{F}_{2}$ & 0.984 & 0.0395 & 5.33 & 0.962 & 0.264 & 10.32 & 0.982 & 0.2115 & 5.30 & 0.953 & 0.0031 & 1.64 & 10.90 & 0.978 & 7.06 \\
\hline $\mathbf{F}_{3}$ & 0.991 & 0.0594 & 7.65 & 0.988 & 0.0329 & 5.23 & 0.995 & 0.2615 & 3.88 & 0.992 & 0.0039 & 1.67 & 3.98 & 0.996 & 3.86 \\
\hline $\mathbf{F}_{4}$ & 0.947 & 0.161 & 39.4 & 0.945 & 0.049 & 9.12 & 0.961 & 0.3957 & 10.26 & 0.999 & 0.0026 & 1.94 & 1.10 & 0.965 & 17.37 \\
\hline
\end{tabular}

of drug release, the in vitro results were fitted to the Korsmeyer-Peppas equation. All formulations showed values of $n>1$, indicating that the drug release mechanism was non-Fickian super case II transport. Therefore it seems that drug release depends upon swelling, relaxation, and polymer erosion $(12,16,17)$.

\section{CONCLUSION}

The results of this study demonstrate that LBG, in the form of a compression coating, is a potential carrier for colonic-specific drug delivery systems that possess acceptable physical characteristics. This polysaccharide is capable of retarding the release of core materials until they reach the colon, an environment rich in bacterial enzymes that degrade the LBG allowing drug release. Stability studies indicated no significant change in physical appearance, drug content, and in vitro release pattern. Moreover, no physical or chemical interaction was evident from FTIR studies, indicating stability of ibuprofen in the prepared tablets.

\section{ACKNOWLEDGMENT}

The authors would like to thank the authority of Dayananda Sagar College of Pharmacy, Karnataka, India, for their support.

\section{CONFLICT OF INTEREST}

The authors report no conflicts of interest in this work.

\section{REFERENCES}

1. Jain, S. K.; Jain, A. Target-specific drug release to the colon. Expert Opin. Drug Deliv. 2008, 5 (5), 483-498.

2. Chourasia, M. K.; Jain, S. K. Pharmaceutical approaches to colon targeted drug delivery systems. J. Pharm. Pharmaceut. Sci. 2003, 6 (1), 33-66.

3. Sinha, V. R.; Kumria, R. Microbially triggered drug delivery to the colon. Eur. J. Pharm. Sci. 2003, 18 (1), 3-18.

4. Dey, P.; Sa, B.; Maiti, S. Carboxymethyl ethers of locust bean gum-A review. Int. J. Pharm. Pharm. Sci. 2011, 3 (2), 4-7.

5. Shah, N.; Shah, T.; Amin, A. Polysaccharides: a targeting strategy for colonic drug delivery. Expert Opin. Drug Deliv. 2011, 8 (6), 779-796.

6. Salunkhe, K. S.; Kulkarni, M. V. Formulation and in-vitro evaluation of dextrin matrix tablet of ibuprofen for colon specific drug delivery. Pak. J. Pharm. Sci. 2008, 21 (1), 17-20.

7. Gohel, M. C.; Nagori, S. A. A novel colonic drug delivery system of ibuprofen. Asian J. Pharmaceut. 2009, 3 (3), 233-239. 
8. The United States Pharmacopeia and National Formulary USP 30-NF 25; The United States Pharmacopeial Convention, Inc.: Rockville, MD, 2007.

9. Jenita, J. J. L.; Vijaya, K.; Suma, R.; Bincy, R.; Ayesha, $\mathrm{S}$. Formulation and evaluation of compression coated tablets of mezalazine for colon delivery. Int. J. PharmTech Res. 2010, 2 (1), 535-541.

10. Chithaluru, K.; Tadikonda, R. R. Formulation and Evaluation of Microbially triggered compression coated tablets of Ketorolac Tromethiamine. Der Pharmacia Lettre 2011, 3 (4), 29-39.

11. Thakkar, V. T.; Shah, P. A.; Soni, T. G.; Parmar, M. Y.; Gohel, M. C.; Gandhi, T. R. Goodness-of-Fit ModelDependent Approach for Release Kinetics of Levofloxacin Hemihydrates Floating Tablet. Dissolution Technol. 2009, 16 (1), 35-39.

12. Khamanga, S. M.; Walker, R. B. Drug Transport Mechanisms from Carbopol/Eudragit Verapamil Sustained-Release Tablets. Dissolution Technol. 2011, 18 (3), 30-38.
13. Wang, J.; Somasundaran, P. Study of galactomannose interaction with solids using AFM, IR and allied techniques. J. Colloid Interface Sci. 2007, 309 (2), 373-383.

14. Bhosale, A. V.; Hardikar, S. R.; Patil, N.; Patel, U.; Sumbe, Y.; Jagtap, R. Formulation and In-vitro Evaluation of Microbially triggered ibuprofen Delivery for Colon targetting. Int. J. PharmTech Res. 2009, 1 (2), 328-333.

15. Bashardoust, N.; Jenita, J. L.; Zakeri-Milani, P. Preparation and In vitro Investigation of Chitosan Compressed Tablets for Colon Targeting. Adv. Pharm. Bull. 2011, 1 (2), 87-92.

16. Asghar, L. F.; Chure, C. B.; Chandran, S. Colon Specific Delivery of Indomethacin: Effect of Incorporating $\mathrm{pH}$ Sensitive Polymers in Xanthan Gum Matrix Bases. AAPS PharmSciTech 2009, 10 (2), 418-429.

17. Siepmann, J.; Peppas, N. A. Modeling of drug release from delivery systems based on hydroxypropyl methylcellulose (HPMC). Adv. Drug Deliv. Rev. 2001, 48 (2-3), 139-157. 